\title{
TRANSTORNO DE DÉFICIT DE ATENÇÃO E HIPERATIVIDADE: CARACTERÍSTICAS, DIAGNÓSTICO E FORMAS DE TRATAMENTO
}

\author{
ATTENTION DEFICIT HYPERACTIVY DISORDER (ADHD): CHARACTERISTICS, \\ DIAGNOSIS AND TREATMENT
}

\author{
Eneida Maria Leone de Souza \\ Yara Kuperstein Ingberman ${ }^{2}$
}

\begin{abstract}
RESUMO
O Transtorno de Déficit de Atenção e Hiperatividade (TDAHI) possui como características nucleares desatenção, hiperatividade e impulsividade. O DSM-IV define vários critérios para o diagnóstico de tal transtorno, que englobam diferentes sintomas de relativas características, em dois módulos sendo um referente à desatenção e outro, à hiperatividade e impulsividade, além de critérios com relação ao tempo de existência de sintomas e idade de início (sendo necessário que o aparecimento dos sintomas seja anterior aos sete anos). Desta forma, considera-se que um adulto apresenta TDAHI se tiverem sido observados sintomas na infância. Existem características adicionais que podem ser encontrados em indivíduos com TDAHI, dentre elas a desorganização, dificuldade no relacionamento interpessoal, relacionamento pobre com pares e irmãos. Portanto, o TDAHI leva a grandes e sérias implicações nos diferentes contextos: social, familiar, acadêmico e/ou profissional. Sendo assim, visualiza-se como de fundamental importância o diagnóstico e o início de tratamentos precoces para o TDAHI, evitando-se maiores conseqüências psicológicas, que os distúrbios comórbidos ocorram e que surjam grandes prejuízos na vida adulta. Um tratamento eficaz envolve a combinação de medicamento e psicoterapia. As medicações mais utilizadas são os psicoestimulantes, e as intervenções psicoterápicas comportamentais podem seguir pressupostos teóricos cognitivistas, ou baseados na Análise do comportamento ou ainda em ambos. É importante considerar que a seleção de estratégias para tratamento deve ser baseada em cada criança individualmente. Também têm papel no tratamento o apoio e compreensão da família e das pessoas que mais convivem com a criança.
\end{abstract}

Palavras-chave: déficit; atenção; hiperatividade.

\begin{abstract}
The Attention Deficit-Hyperactivy Disorder (ADHD) have as main characteristics, lack of attention, hyperactivity and impulsiveness. The DSM-IV defines several criteria for diagnosis of such disorders, comprehending different symptoms of relative characteristics in two modules. One concerning lack of attention and the other, hyperactivity and impulsiveness, besides the criteria concerning the length of existence and starting age (necessarily under 7 years old), therefore an adult will show ADHD if observation has been made during early childhood. There are additional characteristics that may be found in ADHD, such as lack of organization, interpersonal relationship deficiency, poor relationship within relatives and brothers. In other words, the ADHD bring deep and serious implication on different contexts: social, family, academic and/or professional. Considering the fact, it is of fundamental importance the early diagnosis and treatment for the ADHD, avoiding heavy psychological
\end{abstract}

\footnotetext{
${ }^{1}$ Psicóloga pela UFPR.

${ }^{2}$ Mestre e Doutora em Psicologia Clínica pela USP; Professora do Mestrado em Psicologia da Infância e da Adolescência da UFPR. Pç. Santos Andrade, 50 - térreo - 80020-240 Curitiba - PR. ingberman@col.psic.com.br.
} 
consequences and severe injury while adult. An efficient treatment should combine remedy and psychotherapy intervention. It is important to consider that strategic selection for treatment must be based on each child alone. It is also of relevant significance the family and friends support and comprehension with the child.

Key words: deficit; attention; hyperactivity.

\section{INTRODUÇÃO}

É comum na infância surgirem comportamentos de hiperatividade e déficit de atenção levando a fracassos escolares (Topczewski, 1999). Tais fracassos são freqüentemente associados ao retardo mental. Entretanto, já foi avaliado que o prejuízo de inteligência nestas crianças é mínimo, o que levou inclusive a rotulá-las como "mínima disfunção de inteligência" (Erickson, 1998). Apesar de não ser um distúrbio essencialmente infantil, a forma adulta só pode ser diagnosticada se houve ocorrência de sintomas na infância.

As características nucleares do Transtorno de Déficit de Atenção e Hiperatividade (TDAHI) são: desatenção, hiperatividade e impulsividade (Reinecke, Dattilio, \& Freeman, 1999; Kaplan \& Sadock, 1994; Flick, 1998). Há profissionais que acreditam que o diagnóstico pode ser feito somente pelos critérios do DSM-IV.

O presente artigo aborda, através de revisão bibliográfica, características de comportamentos de hiperatividade e déficit de atenção, além de formas utilizadas para diagnóstico e tratamento do Transtorno de Déficit de Atenção, visando fornecer um panorama geral de comportamentos que acompanham tal transtorno e/ou decorrem dele, bem como conseqüências de tais comportamentos para a vida do indivíduo.

\section{DIAGNÓSTICO}

O sistema americano (DSM-IV) define critérios diagnósticos para tal transtorno em dois módulos, sendo um relativo à desatenção e outro, à hiperatividade e impulsividade.

Módulo 1: Seis ou mais dos seguintes sintomas de desatenção persistiram por pelo menos seis meses em grau de- sadaptativo e inconsistente com o nível de desenvolvimento da criança.

a) Freqüentemente não presta atenção a detalhes e comete erros por descuido nas tarefas escolares, trabalhos ou outras atividades;

b) Freqüentemente tem dificuldade em manter a atenção em tarefas ou jogos;

c) Freqüentemente parece não escutar quando Ihe falam diretamente;

d) Freqüentemente não segue as instruções até o final e não termina as tarefas escolares, atribuições domésticas ou deveres no trabalho (que não seja devido a um comportamento opositivo ou incapacidade de entender as instruções);

e) Freqüentemente tem dificuldades em organizar tarefas e atividades;

f) Freqüentemente evita, desgosta ou é relutante em se engajar em tarefas que exigem esforço mental mantido (tais como tarefas escolares ou domésticas);

g) Freqüentemente perde coisas necessárias para tarefas e atividades, tais como brinquedos, obrigações escolares, lápis, livros ou ferramentas;

h) É, com freqüência, facilmente distraído por estímulos externos;

i) É freqüentemente esquecido em atividades diárias.

Módulo 2: Seis ou mais dos seguintes sintomas de hiperatividade e impulsividade persistiram por pelo menos seis meses em grau desadaptativo e inconsciente com o nível de de- senvolvimento da criança.

\section{Hiperatividade:}

a) Freqüentemente agita as mãos ou os pés ou se remexe na cadeira; 
b) Freqüentemente não permanece em sua cadeira em sala de aula ou outras situações nas quais se espera que permaneça sentado;

c) Freqüentemente corre ou escala obstáculos em demasia, nas situações nas quais isto é inapropriado (em adolescentes e adultos, pode ser sensação subjetiva de inquietude);

d) Com freqüência tem dificuldade para brincar ou se envolver silenciosamente em atividades de lazer;

e) Freqüentemente está "a mil" ou "a todo vapor";

f) Freqüentemente fala em demasia.

\section{Impulsividade:}

a) Freqüentemente responde precipitadamente, antes de as perguntas terem sido completadas;

b) Com freqüência tem dificuldades para aguardar a sua vez;

c) Freqüentemente se intromete ou interrompe os outros.

Conforme a prevalência de sintomas nos módulos, o DSM-IV propõe tipos:

- Predominantemente desatento: se o módulo 1 é satisfeito e o módulo 2 não;

- Predominantemente hiperativo/impulsivo: se o módulo 2 é satisfeito e o módulo 1 não;

- Tipo misto: se os dois módulos são satisfeitos.

O aparecimento dos sintomas deve ser anterior aos sete anos de idade; eles precisam estar presentes em dois ou mais contextos, causar prejuízo na função social ou acadêmica e não serem mais bem explicados por alguma desordem mental.

Para a avaliação de sintomas numa criança é necessário que se avalie a história de desenvolvimento a partir de informações com os pais, professores e com a própria criança (Erickson, 1998; Flick, 1998). Estas informações podem ser obtidas por entrevistas ou por métodos de avaliação tais como testes, que buscam compreender como a criança se comporta nos diferentes contextos em que atua. Muitas vezes o diagnóstico deve ser validado por uma equipe multiprofissional (médicos, psicólogos, fonoaudiólogos e psicopedagogos), onde possam ser avaliados os sintomas em relação ao que se espera para determinada faixa etária.

Cabe avaliar ainda todo o contexto do qual a criança diagnosticada como hiperativa faz parte. Isto porque, muitas vezes, o diagnóstico na criança vem apenas refletir um padrão disfuncional de relações em toda uma família ou em todo um grupo. Deste modo, é importante ter em vista que a hiperatividade não pode ser tratada de modo simplista ou da forma como se trata uma enfermidade orgânica.

Os profissionais precisam tomar o cuidado de não ver no rótulo de hiperatividade o "problema" de uma criança solucionado. Ou seja, ter satisfeitas as características para se diagnosticar a hiperatividade não deve acomodar o profissional e as pessoas ao redor da "criança-problema". Não se deve deixar de avaliar todas as relações da criança, já que estas podem estar envolvidas diretamente com a criação e/ou com a manutenção do problema sobre o qual se levanta a queixa. Sendo assim, de maneira alguma se deve considerar que só medicação basta para tratar o comportamento denominado hiperativo, pois tal comportamento pode estar expressando um conjunto de situações sobre as quais é preciso atuar. (Sucupira,1986)

\section{CARACTERÍSTICAS DO TDAHI E TRANSTORNOS QUE PODEM SE ASSOCIAR}

Diversos autores têm observado que há componente genético na determinação do TDAHI, principalmente em estudos onde se vê que é mais freqüente a doença aparecer nos dois gêmeos monozigóticos do que nos dizigóticos e onde se vê presença de psicopatologias 
em pais de crianças com TDAHI (Erickson, 1998; Kaplan, 1994; Mattos, 1999). Dentre os fatores neuroanatômicos que podem ser encontrados como evidência do TDAHI pode-se citar a diminuição da atividade na região pré-frontal, (Flick, 1998; Rubia et al., 1999) evidenciando especialmente a deficiência em formular/responder a perguntas, no controle motor superior, aguardar recompensas futuras, regular a atenção.

O TDAHI afeta 3 a 5\% das crianças em idade pré-escolar (Freeman, 1999; Kaplan, 1994; Erickon, 1998; Disney, Elkins, Mc Gue \& lacono, 1999). Além disso, 50\% das crianças que apresentam o transtorno terão persistência de sintomas na vida adulta (Reinecke et al., 1999; Baptiste, 1997).

Existem características adicionais que podem ser encontradas em indivíduos com TDAHI. A desorganização é uma destas características e pode ser visualizada pela incapacidade e deficiência em lembrar coisas importantes, preparar projetos e testes, encontrar o que se procura. Problemas de memória parecem surgir em atividades rotineiras, o que pode ser exemplificado por esquecimentos de objetos ou informações importantes que lhes sejam importantes para a execução de alguma atividade. Cabe colocar a inconsistência e flutuações no comportamento como freqüentemente presentes em indivíduos com TDAHI ora apresentando-se de uma forma, ora de forma oposta (Flick, 1998). Relacionamento pobre com pares e irmãos, dificuldade no relacionamento interpessoal, caracterizado por interpretações maldosas sobre comentários sociais e comportamentos inapropriados também podem ocorrer. Quando a agressividade está presente, o prognóstico é pior, visualizando-se um desrespeito para com o outro. Auto-imagem e autoconceito pobres levam tais indivíduos a se relacionarem melhor com indivíduos mais jovens ou com o mesmo problema, além de se denominarem rejeitados e mal-ajustados. Ainda podem apresentar sinais de estarem adormecidos e/ou sonhando durante o dia. Outra característica que pode acontecer é a deficiência na coordenação motora, especialmente com relação à coordenação fina, caracterizando-se rudeza e indelicadeza em suas produções.

As crianças com esse transtorno, portanto, se apresentam agitadas, inquietas, impulsivas (não conseguindo esperar sua vez, intrometendo-se na fala dos outros), com dificuldades para manter a atenção. Tendo todas estas características em vista, considerando-se que elas ocorrem em conjunto com as nucleares (impulsividade, desatenção e hiperatividade), é possível avaliar as grandes e sérias implicações do TDAHI nos diferentes contextos: social, familiar, acadêmico e/ou profissional.

Visualiza-se então como de fundamental importância o diagnóstico e o início de tratamentos precoces para o TDAHI. Quanto mais cedo é feito o diagnóstico, menores são as conseqüências psicológicas na criança ao longo dos anos, e precocemente identifica-se a existência de outras doenças associadas (Mattos, 1999). Sendo assim, crianças e adultos com o transtorno, quando tratados precocemente, podem ter uma vida satisfatória e produtiva.

Dentre os distúrbios comórbidos (dois distúrbios associados com maior freqüência do que esperado pelo acaso) do TDAHI podem-se citar transtornos de humor (como as depressões) e transtorno de conduta (ou também denominado transtorno desafiador de oposição). A comorbidade com transtorno de conduta tem sido descrita em 30 a 50\% dos casos de TDAHI. O transtorno de conduta aumenta o risco de uso e abuso de substâncias variadas (como álcool, maconha, nicotina, cocaína), especialmente em adolescentes (Disney et al., 1999).

O transtorno (ou desordem) de conduta pode ser suspeitado quando, além de serem perturbadoras, a impulsividade e a hiperatividade violam as normas sociais. A existência de sintomas depressivos de leve intensidade e isolados não representa necessariamente comorbidade com depressão. Quando a distratibilidade e a baixa tolerância à frustração caracterizam-se por tristeza e perda de interesse, além de irritabilidade, um transtorno depressivo pode ser diagnosticado em conjunto com o TDAHI. Percebe-se, portanto, que o tratamento precoce do TDAHI traz benefícios evidentes e significativos nas situações cotidianas, acadêmicas e sociais.

TRATAMENTO: MEDICAÇÕES E TÉCNICAS PSICOTERÁPICAS UTILIZADAS 
É importante considerar que um tratamento mais eficaz para um TDAHI envolve a combinação de medicamento e psicoterapia (Baptiste, 1997; Kaplan, 1994; Erickson, 1998; Flick, 1998). As medicações mais utilizadas são os psicoestimulantes sendo as mais eficazes metilfenidato (Ritalina), dextroanfetamina (Dexedrina) e pemoline (Cybert) melhorando a atenção e diminuindo a atividade e impulsividade na maior parte das crianças com TDAHI. Entretanto tais medicações podem causar efeitos colaterais como dor de cabeça, irritabilidade, sentimento de tristeza, além de supressão do crescimento após longo tempo de uso. A dose e a aceitação da medicação pela criança devem ser avaliadas, pois pode haver necessidade de alteração visando minimizar os efeitos colaterais (Flick, 1998). O metilfenidato é o medicamento mais utilizado, o pemoline é mais atrativo para crianças, já que é diluível, mas leva mais tempo para gerar efeitos.

O critério médico deve prevalecer sobre pressões de pais e professores, embora estes possam contribuir para a decisão da medicação, avaliando o impacto desta na vida acadêmica e social da criança. Os psicoestimulantes agem aumentando a atividade pré-frontal por meio da maior ação do receptor GABA mediante o aumento de dopamina no núcleo estriado (Baptiste, 1997). Quando há comorbidade alguns antidepressivos têm sido utilizados (Baptiste, 1997; Kaplan, 1994).

A psicoterapia combinada pode levar à redução da dosagem da medicação (Flick, 1998). Pode-se caracterizar as intervenções psicoterápicas comportamentais em duas abordagens: as cognitivistas e as baseadas na Análise do Comportamento. Ambas as abordagens podem utilizar técnicas como procedimento adjunto no manejo clínico de uma criança com TDAHI, porém os pressupostos teóricos que fundamentam as técnicas diferem nas duas abordagens. Dentre as técnicas utilizadas nestas intervenções pode-se citar: treinamento de auto-instru-ção, treinamento na resolução de problemas sociais, automonitoração, auto-avaliação e autoreforço.

Quanto aos pressupostos teóricos, para a abordagem cognitivista os processos simbólicos medeiam a ação e, portanto, o pensamento é causa dos comportamentos, ou seja, considera-se que, mudando-se o pensamento, pode-se mudar um comportamento. Já para a abordagem baseada na Análise do Comportamento, o comportamento é função de eventos ambientais, é produto de um encadeamento de estímulos e respostas, e o pensamento é considerado uma classe de respostas como outra qualquer. Sendo assim, nesta abordagem considera-se que o indivíduo possui diferentes possibilidades de respostas para uma situação, e sua escolha se dá conforme sua história de aprendizagem e de adaptação; portanto, a mudança de um comportamento envolve alterações em todo um encadeamento.

Cabe deste modo ressaltar que em ambas as abordagens as técnicas podem compor os procedimentos utilizados pelo terapeuta mas não são os únicos. O terapeuta desenvolverá com seu cliente o manejo clínico necessário para trabalhar todo o contexto envolvido com a manutenção dos comportamentos que caracterizam o TDAHI, avaliando alternativas de extinguir comportamentos disfuncionais, conforme sua visão teórica. Portanto, a seguir serão descritas algumas técnicas utilizadas no tratamento psicoterápico do TDAHI, ilustrando-se instrumentos que podem compor este tratamento.

O treinamento de auto-instrução baseia-se na premissa proposta por alguns autores como Luria e Vygostski de que as crianças aprendem a regular seu comportamento pelo autodiscurso oculto, ou seja, se dão as instruções "internamente" para realizar as tarefas (Reinecke et al., 1999; Mattos, 1999). Dados sugerem que, em crianças com TDAHI, há um retardo no desenvolvimento do discurso autodirigido. A auto-instrução pode ser utilizada para regular a impulsividade e desatenção. Inicialmente o instrutor demonstra a tarefa autoorientando-se; depois a criança deve fazer a tarefa mediante instruções; a criança deverá então fazê-la enquanto sussurra as instruções para posteriormente realizar a tarefa orientandose pelo discurso privado (Reinecke et al., 1999).

O treinamento na resolução de problemas sociais pode ensinar a criança a lidar com a expressão de suas necessidades de forma adequada, socialmente aceita e realista. $O$ treinamento em resolução de problemas sociais envolve ensinar a criança a: reconhecer que tem um problema; buscar alternativas para solucioná-lo; avaliar as conseqüências das 
diferentes alternativas, decidir qual alternativa tentar, revisar resultados. Tem por base a idéia de que crianças com TDAHI têm pouco controle sobre os impulsos e não levam em consideração diferentes alternativas para solucionar seus problemas. Entretanto, a literatura tem demonstrado que esta técnica psicoterápica utilizada de forma isolada não produz mudanças significativas no comportamento das crianças com TDAHI (Reinecke et al., 1999).

A técnica de autocontrole "La Tortuga" proposta por Schneider \& Robin (1992), especialmente, para crianças de sete a oito anos, que associa técnicas de: interrupção da cadeia de conduta disruptiva por uma palavra-chave, solução de problemas e relaxamento, tem se mostrado benéfica para o tratamento de hiperatividade, impulsividade e problemas de conduta (Camañes \& Colas, 1992). O primeiro passo é selecionar em quais condutas disruptivas se gostaria que uma criança utilizasse o autocontrole com a palavra Tortuga. Ensina-se a criança a responder a palavra "tartaruga" (tortuga) como palavra-chave, a partir de uma história inicial. Conta-se a história de uma tartaruga que aprendeu a se esconder dentro de sua carapaça ao se sentir ameaçada ou quando se encontrava raivosa sem saber muito bem o motivo. Faz-se uma analogia com a criança ensinando-a a encolher-se ao ouvir a palavra "tartaruga". A criança deve ser incentivada a usar a técnica em diferentes contextos (casa, escola, ...) recebendo reforço social (expressões de afeto, estima, ...) ou material (balas, doces, ...) imediata e contingentemente à resposta de "tartaruga".

Inicialmente delimitam-se períodos de tempo em que a técnica deve ser aplicada, dá-se a instrução para que a criança aplique. Com a continuidade de utilização incentiva-se o uso espontâneo da técnica em qualquer hora do dia, identificando as situações em que esta é apropriada. A "tartaruga" é apropriada quando uma criança é vítima de uma conduta agressiva de outra criança, ou quando uma criança a utiliza para interromper a realização de uma conduta agressiva própria. Pode-se ver como inapropriada a utilização da técnica por crianças com único objetivo de obter reforços.

$\mathrm{Na}$ história da tartaruga, esta também aprendeu a relaxar seus músculos para entrar na carapaça, fazendo que a tensão desaparecesse em definitivo assim como os maus sentimentos. Então o aplicador da técnica deve orientar a criança a relaxar após realizar a "tartaruga" com a finalidade de suspender qualquer tendência a condutas e emoções negativas posteriores à "tartaruga". Como última etapa da técnica está o treinamento na situação problemática, criando alternativas de solução e selecionando a melhor alternativa. A aplicação da "tartaruga" é mais vantajosa na escola já que, além da colaboração do professor, os alunos podem apoiar uns aos outros para a utilização da técnica (Schneider \& Robin, 1992).

A técnica de auto-avaliação e auto-reforço é formulada a partir da idéia de que crianças com TDAHI provavelmente não avaliam adequadamente seu desempenho numa tarefa e, dificilmente, fazem colocações positivas acerca deste. Procedimento de automanejo como quando se propõe que estudantes e professores avaliem condutas adequadas daqueles sob os mesmos critérios, fornecendo-se pontos aos estudantes tanto pela conduta adequada quanto pela coincidência entre a avaliação do professor e auto-avaliação, enfatizam a auto-avaliação e auto-reforço. Gradualmente, o professor aumenta a independência do estudante, e incentiva-se a generalização do automanejo para outros contextos (Reinecke et al., 1999).

Há pesquisas preliminares que trazem resultados positivos desta técnica (Barkley et al., 1984, apud Reinecke et al., 1999).

É importante considerar que cada criança tem respostas próprias ao tratamento e, portanto, a seleção de estratégias deve ser baseada em cada uma individualmente. Deve-se monitorar as respostas das crianças ao tratamento psicoterápico de forma individual, utilizandose, por exemplo, de gráficos, onde as melhoras podem ser vistas mais claramente. Conforme os sintomas da criança e os ambientes nos quais convive, as intervenções podem ser incluídas em casa, na escola e em ambientes da comunidade. Neste caso o terapeuta deve orientar pais, professores e até colegas (Reinecke et al., 1999).

\section{CONCLUSÃO}

De fundamental relevância é o envolvimento da família e dos professores na busca de uma melhora para a criança que vem apresentando dificuldades. Sendo assim, a família 
precisa compreender adequadamente as dificuldades de criança, apoiá-la valorizando pequenos ganhos, incentivá-la a realizar atividades para as quais tenha mais habilidade e não rotulá-la. Os professores precisam ter conhecimentos sobre o TDAHI, estimular a criança e estar dispostos a dialogar com ela. A observação do ambiente é ainda parte de tratamento, já que 0 déficit de atenção pode ser influenciado por um ambiente não silencioso, com determinação rígida de tempo para realizar a atividade (Mattos, 1999).

Percebe-se, desta forma, que o TDAHI constitui um transtorno que causa prejuízos significativos nos diferentes contextos da vida de uma pessoa: social, familiar, acadêmica e/ou profissional. Entretanto, tais prejuízos podem ser minimizados desde que tratados por profissionais capacitados, associando-se medicação e psicoterapia. Ressalta-se também a grande importância de se fazer diagnóstico e tratamento precoces a fim de evitar que outros transtornos se associem e/ou outros problemas de comportamento ocorram.

Cabe assim aos profissionais que estudam e trabalham com o TDAHI levar ao conhecimento do público leigo a existência deste transtorno e as suas implicações, possibilitando que estas pessoas atentem precocemente para possíveis sintomas nas crianças que as rodeiam, contribuindo para que não se discriminem tais crianças e sim, Ihes forneçam um tratamento adequado e satisfatório.

\section{REFERÊNCIAS BIBLIOGRÁFICAS}

Baptiste, G. N. (1997). Neuropsiquiatria del transtorno por déficit de aténcion e hiperactividade (TDAH). Psiquiatria Biológica, 2 (5), 85-97.

Camañes, T. B. \& Colas, M. G. (1992). Aplicación de la técnica de autocontrol "La Tortuga". Em T. Bonet (Org.), Problemas psicológicos en la infancia: Programas de intervencción (p. 107-125). Valência: Romolibro-Cinteco.

Disney, E. R.; Elkins, I. J.; Mc Gue, M. \& lacono, W. G. (1999). Effects of ADHD, conduct disorder and gender on substance use and abuse in adolescents. The American Journal of Psychiatry, 156(10), 1.515-1.521.

DSM-IV (1995). Manual diagnóstico e estatístico de transtornos mentais. 4. ed. Porto Alegre: Artes Médicas.

Erickson, M. (1998). Behavior disorders of children and adolescents. New Jersey: Prentice-Hall Inc.

Flick, G. (1998). ADD/ADHD - behavior change resource kit. New York: The Center for Applied Research in Education.

Kaplan, H. I. \& Sadock, B.J. (1994). Kaplan and Sadock's synopsis of psychiatry: Behavioral sciences, clinical psychiatry. $7^{\text {th }}$ ed. Maryland: Sans Tache.

Reinecke, M. A., Dattilio, F.M. \& Freeman, A. (1999). Terapia cognitiva com crianças e adolescentes: Manual para a prática clínica. Porto Alegre: Artes Médicas.

Rubia, K.; Overmeyer, S.; Taylor, E.; Brammer, M.; Williams, S.; Simmons, A. \& Bullmore, E.T. (1999). Hypofrontality in attention deficit hyperactivity disorder during higher-order motor control: A study with functional MRI. The American Journal of Psychiatry, 156 (6), 891-896.

Schneider, M. \& Robin, A. (1992). La técnica de "la tortuga": Un método para o autocontrol de la conducta impulsiva. Em T. Bonet (Org.), Problemas psicológicos de la infancia: Programas de intervencción (p.127163) Valencia: Romolibro - Cinteco.

Sucupira, A. C. S. L. (1986). Hiperatividade: Doença ou rótulo? Cadernos Cedes, 15, 30-43.

Topczewiski, A. (1999). Hiperatividade: Como lidar? São Paulo: Casa do Psicólogo/Cortez.

Mattos, P. (1999). TDAHI: Diagnóstico e causas. Obtido em 1ํ de outubro de 1999 do Word Wide Web

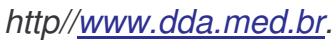

